\title{
Early cavopulmonary anastomosis in very young infants after the Norwood procedure: Impact on oxygenation, resource utilization, and mortality
}

Robert D. B. Jaquiss, $M D^{a, b}$ Nancy S. Ghanayem, $M D^{\mathrm{b}, \mathrm{c}}$ George M. Hoffman, MD ${ }^{b, c, d}$ Raymond T. Fedderly, $M D^{b, e}$ Joseph R. Cava, MD, PhD ${ }^{\mathrm{b}, \mathrm{c}}$ Kathleen A. Mussatto, RN, BSN ${ }^{b}$ James S. Tweddell, MD ${ }^{a, b}$
From the Division of Pediatric Cardiothoracic Surgery, Medical College of Wisconsin, Milwaukee, Wis, ${ }^{\text {a }}$ Children's Hospital of Wisconsin, Milwaukee, Wis, ${ }^{\text {b }}$ and the Divisions of Pediatric Critical Care, ${ }^{\mathrm{c}}$ Pediatric Anesthesia, ${ }^{\mathrm{d}}$ and Pediatric Cardiology, ${ }^{\mathrm{e}}$ Medical College of Wisconsin, Milwaukee, Wis.

Read at the Twenty-ninth Annual Meeting of The Western Thoracic Surgical Association, Carlsbad, Calif, June 18-21, 2003.

Received for publication June 16, 2003; revisions requested Sept 30, 2003; revisions received Oct 6, 2003; accepted for publication Oct 28, 2003.

Address for reprints: Robert D. B. Jaquiss, MD, 9000 W Wisconsin Ave, M.S. 715, Milwaukee, WI 53226 (E-mail: rjaquiss @ chw.org).

J Thorac Cardiovasc Surg 2004;127:982-9 $0022-5223 / \$ 30.00$

Copyright $\odot 2004$ by The American Association for Thoracic Surgery

doi:10.1016/j.jtcvs.2003.10.035
Background: The optimal timing of second-stage palliation after Norwood operations remains undefined. Advantages of early cavopulmonary anastomosis are early elimination of volume load and shortening the high-risk interstage period. Potential disadvantages include severe cyanosis, prolonged pleural drainage and hospitalization, and excess mortality. We reviewed our recent experience to evaluate the safety of early cavopulmonary anastomosis.

Methods: Eighty-five consecutive patients undergoing post-Norwood operation cavopulmonary anastomosis were divided into group I (cavopulmonary anastomosis at $<4$ months; $\mathrm{n}=33$ ) and group II (cavopulmonary anastomosis at $>4$ months; $\mathrm{n}$ =52). Groups were compared for age; size; early and late mortality; preoperative, initial postoperative, and discharge oxygen saturation; and duration of mechanical ventilation, intensive care unit stay, pleural drainage, and hospitalization.

Results: Group I patients were younger than group II patients (94 \pm 21 days vs 165 \pm 44 days, respectively; $P<.001)$ and smaller $(4.8 \pm 0.8 \mathrm{~kg}$ vs $5.8 \pm 0.9 \mathrm{~kg} ; P$ $<.001$ ). The preoperative oxygen saturation was not different (group I, 75\% \pm $10 \%$; group II, $78 \% \pm 8 \% ; P=.142$ ). The oxygen saturation was lower immediately after surgery in group I compared with group II $(75 \% \pm 7 \%$ vs $81 \% \pm 7 \%$, respectively; $P<.001$ ) but not by discharge (group I, $79 \% \pm 4 \%$; group II, $80 \%$ $\pm 4 \%)$. Younger patients were ventilated longer (62 \pm 86 hours vs $19 \pm 42$ hours; $P=.001)$, in the intensive care unit longer $(130 \pm 111$ hours vs $104 \pm 94$ hours; $P=.049)$, hospitalized longer $(12.5 \pm 11.5$ days vs $10.3 \pm 14.8$ days; $P=.012)$, and required longer pleural drainage (106 \pm 45 hours vs $104 \pm 93$ hours; $P=.046)$. Hospital survival was $100 \%$ in both groups. Actuarial survival to 12 months was $96 \% \pm 4 \%$ for group I and $96 \% \pm 3 \%$ for group II.

Conclusions: Early cavopulmonary anastomosis after the Norwood operation is safe. Younger patients are more cyanotic initially after surgery and have a longer duration of mechanical ventilation, pleural drainage, intensive care unit stay, and hospitalization.

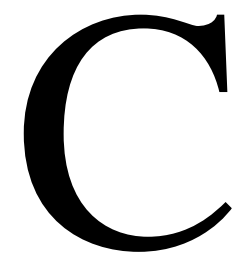
ontemporary management of children with univentricular hearts and aortic arch obstruction includes an initial modified Norwood operation, followed months later by conversion to a superior vena caval source of pulmonary blood flow and, finally, by 2 to 3 years of age, the addition of inferior caval blood to pulmonary inflow to achieve the complete Fontan physiology. Conversion of the source of pulmonary blood from a systemic pulmonary shunt to a cavopulmonary anasto- 
mosis is desirable for several theoretical reasons ${ }^{1,2}$ : to change from an inefficient parallel circulation to a more efficient series circulation, to reduce the effects of chronic volume loading on the single ventricle, ${ }^{3}$ to protect the pulmonary vasculature from systemic arterial pressure, to increase systemic diastolic blood pressure, to normalize coronary blood flow patterns, ${ }^{4}$ and to end the period of vulnerability to sudden death, which is known to extend from stage I to stage II palliation. ${ }^{5-7}$ Despite these potential benefits of conversion to cavopulmonary physiology, optimal timing of the second-stage operation remains unsettled. Potential disadvantages of very early operation include excessive cyanosis, prolonged and complicated hospital stays, and excess mortality. ${ }^{1,2,8-10} \mathrm{We}$ have recently instituted an aggressive home monitoring program for patients after Norwood operation that has led in some cases to earlier performance of stage II palliation. ${ }^{7}$ Even in patients without events detected by home monitoring, we have tended to perform second-stage palliation at an earlier age. To determine the effect of earlier cavopulmonary anastomosis, we compared a group of children who underwent unusually early operation with a contemporaneous group who underwent operation at a more conventional age.

\section{Patients and Methods}

\section{Patient Population}

The medical records of 85 consecutive patients undergoing cavopulmonary anastomosis after an initial Norwood procedure between January 1998 and February 2003 at the Children's Hospital of Wisconsin were reviewed. These patients were derived from an original cohort of 86 consecutive patients undergoing Norwood operations, 1 of whom died of mesenteric ischemia at 114 days of age. All children underwent unilateral or bilateral bidirectional cavopulmonary anastomosis (CPA), as well as any other indicated procedures, such as atrioventricular valve repair, aortic arch reconstruction, or pulmonary arterioplasty. By institutional policy, recurrent arch obstruction was not addressed at the time of preCPA cardiac catheterization, but instead was relieved surgically at the time of CPA. To determine the effect of age at operation on outcome, the patients were divided into those younger than 4 months at the time of CPA (group I; $\mathrm{n}=33$ ) and those older than 4 months at operation (group II; $n=52$ ). Timing of operation was at the discretion of the attending cardiologist and surgeon. In group I, 24 patients were followed up in the home monitoring protocol, 14 of whom had an event detected (cyanosis, weight loss, or poor weight gain) that led to intervention but not necessarily to early operation. In group II, 22 patients had home monitoring, of whom 7 had an event detected. Demographic information, cardiac anatomy, associated procedures, duration of ventilation, intensive care unit (ICU) stay, duration of chest tube drainage, length of hospitalization, and oxygen saturation $\left(\mathrm{SaO}_{2}\right)$ data at various time points were recorded. Hemodynamic data from cardiac catheterization and on arrival in the ICU after surgery were also tabulated. Permission for the study was obtained from the Institutional Review Board of the Children's Hospital of Wisconsin.

\section{Cardiac Catheterization}

Most patients underwent preoperative cardiac catheterization to assess candidacy for second-stage operation and to identify any anatomic abnormalities necessitating intervention. Hemodynamic variables recorded included pulmonary artery pressure, ventricular end-diastolic pressure, $\mathrm{SaO}_{2}$, and superior vena caval oxygen saturation. Because of difficulties with vascular access or significant shunt narrowing, not all data were available for all patients. The timing of catheterization was variable relative to operation, but in elective situations, the 2 were typically not performed during the same hospitalization.

\section{Operative Technique and Management}

The operations were performed with moderately hypothermic $\left(28^{\circ} \mathrm{C}-32^{\circ} \mathrm{C}\right)$ cardiopulmonary bypass and bicaval venous cannulation. Cold blood cardioplegic arrest was used if intracardiac procedures were performed. A brief period of deep hypothermic circulatory arrest was used if aortic arch reconstruction was necessary. After termination of cardiopulmonary bypass, modified ultrafiltration was used in all patients.

Cavopulmonary anastomoses were constructed in an end-toside fashion after division of the superior vena cava and oversewing of the cardiac end of the vessel. The azygous vein was routinely divided (as was the hemiazygous vein in the case of bilateral superior vena cavae) unless the patient had an interrupted inferior vena cava. All anastomoses were accomplished with running 7-0 polypropylene sutures. If aortic arch narrowing had been identified by preoperative catheterization, the narrowed region was enlarged with cryopreserved allograft pulmonary artery, as were any pulmonary arterial stenoses. Bilateral pleural drains and 2 mediastinal drains were placed in all patients.

Anesthesia management typically consisted of a balanced inhaled opioid technique that used fentanyl-equivalent dosing at 5 to $25 \mu \mathrm{g} / \mathrm{kg}$ and isoflurane at $1 \%$ to $2 \%$. At the discretion of the attending anesthesiologist, regional anesthesia was additionally used (caudal block with $1 \mathrm{~mL} / \mathrm{kg}$ of $0.25 \%$ bupivacaine with epinephrine 1:200,000 plus 30 to $100 \mu \mathrm{g} / \mathrm{kg}$ of epidural morphine). Most children were managed with the intention of immediate postoperative extubation. Intraoperative and immediate postoperative hemodynamic monitoring routinely consisted of a superior vena caval catheter (via the jugular or subclavian vein), a direct atrial catheter, and a radial or femoral arterial catheter. All patients received a milrinone loading dose $(50 \mu \mathrm{g} / \mathrm{kg})$ and an infusion $(0.5$ $\mu \mathrm{g} \cdot \mathrm{kg}^{-1} \cdot \mathrm{min}^{-1}$ ) and low-dose dopamine (3 to $5 \mu \mathrm{g} \cdot \mathrm{kg}^{-1}$. $\min ^{-1}$ ). Some patients also received infusions of epinephrine 0.02 to $0.1 \mu \mathrm{g} \cdot \mathrm{kg}^{-1} \cdot \mathrm{min}^{-1}$ as needed. All children received aprotinin as previously described. ${ }^{11,12}$

\section{ICU Management}

Patients who did not require mechanical ventilation after surgery were maintained on supplemental oxygen at to keep $\mathrm{SaO}_{2}$ greater than $75 \%$. Patients who required mechanical ventilation were managed with pressure-controlled ventilation at the lowest possible mean airway pressure. After recovery from neuromuscular blockade and sedation, mechanical ventilation was withdrawn when patients were breathing spontaneously and comfortably on fractional inspired oxygen concentrations less than $40 \%$, with $\mathrm{SaO}_{2}$ greater than $70 \%$, and with acceptable hemodynamic parameters. 
TABLE 1. Patient diagnoses

\begin{tabular}{lcc}
\hline Diagnosis & $\begin{array}{c}\text { Group I } \\
\text { (n = 33) }\end{array}$ & $\begin{array}{c}\text { Group II } \\
(\mathbf{n}=\mathbf{5 2})\end{array}$ \\
\hline HLHS, aortic atresia & $21(64 \%)$ & $28(54 \%)$ \\
HLHS, aortic stenosis & $6(18 \%)$ & $5(10 \%)$ \\
HLHS, VSD & 0 & $8(15 \%)$ \\
TA, TGA, CoA & $3(9 \%)$ & $2(4 \%)$ \\
DILV, TGA, CoA & $2(6 \%)$ & $3(6 \%)$ \\
Other & $1(3 \%)$ & $6(11 \%)$ \\
\hline
\end{tabular}

$\overline{H L H S}$, Hypoplastic left heart syndrome; VSD, ventricular septal defect; $T A$, tricuspid atresia; TGA, transposition of the great arteries; $C o A$, coarctation of aorta; DILV, double-inlet left ventricle.
TABLE 2. Simultaneous procedures

\begin{tabular}{lcc}
\hline Operation & $\begin{array}{c}\text { Group I } \\
\text { (n = 33) }\end{array}$ & $\begin{array}{c}\text { Group II } \\
\text { (n = 52) }\end{array}$ \\
\hline None & $20(61 \%)$ & $39(75 \%)$ \\
Aortic arch reconstruction & $8(24 \%)$ & $7(13 \%)$ \\
Aortic arch reconstruction and & $1(3 \%)$ & 0 \\
$\quad$ pulmonary arterioplasty & & \\
Pulmonary arterioplasty & $2(6 \%)$ & $1(2 \%)$ \\
Atrioventricular valvuloplasty & $1(3 \%)$ & $2(4 \%)$ \\
Ligate left superior vena cava & 0 & $2(4 \%)$ \\
Pulmonary or systemic venoplasty & $1(3 \%)$ & $1(2 \%)$ \\
\hline
\end{tabular}

aortic stenosis. Approximately $20 \%$ of the patients in each group had other forms of univentricular cardiac anatomy and aortic obstruction.

\section{Preoperative Cardiac Catheterization}

Preoperative cardiac catheterization data were available for 78 patients. Mean pulmonary artery pressures, obtained by crossing the systemic to pulmonary artery shunt, were $14 \pm$ $5 \mathrm{~mm} \mathrm{Hg}$ for group I and $15 \pm 3 \mathrm{~mm} \mathrm{Hg}$ for group II $(P=$ .251). Likewise, ventricular end-diastolic pressures were not different between groups (group I, $13 \pm 4 \mathrm{~mm} \mathrm{Hg}$; group II, $12 \pm 3 \mathrm{~mm} \mathrm{Hg} ; P=.197)$. $\mathrm{SaO}_{2}$ values during catheterization were not different between groups (group I, $76 \% \pm 6 \%$; group II, $78 \% \pm 7 \% ; P=.142$ ), nor were superior vena caval oxygen saturations (group I, 55\% \pm $11 \%$; group II, $55 \% \pm 12 \% ; P=.876$ ).

\section{Operative Details}

A significant number of children required additional surgical procedures at the time of CPA (Table 2). In the younger group, $40 \%$ required simultaneous procedures, and in the older group, $25 \%$ had additional intervention $(P=.227)$. In both groups, most additional procedures were aortic arch reconstructions to treat recurrent aortic arch obstruction. No other procedure was performed in more than 2 patients in either group. The duration of cardiopulmonary bypass was nearly identical for the 2 groups (group I, $81 \pm 28$ minutes; group II, $83 \pm 32$ minutes; $P=.806$ ). Among the patients who required aortic crossclamping, the mean clamp time was identical and very short in each group $(9 \pm 15$ minutes); this reflects the infrequent need for simultaneous intracardiac repair.

\section{Mortality, Mechanical Ventilation, Intensive Care Course, and Hospital Course}

Operative and hospital survival were $100 \%$ in both groups. Actuarial survival to 1 year of age by Kaplan-Meier analysis was $96 \% \pm 4 \%$ in the younger group and $96 \% \pm 3 \%$ in the older group $(P=.962)$. There was 1 death 3 months after 


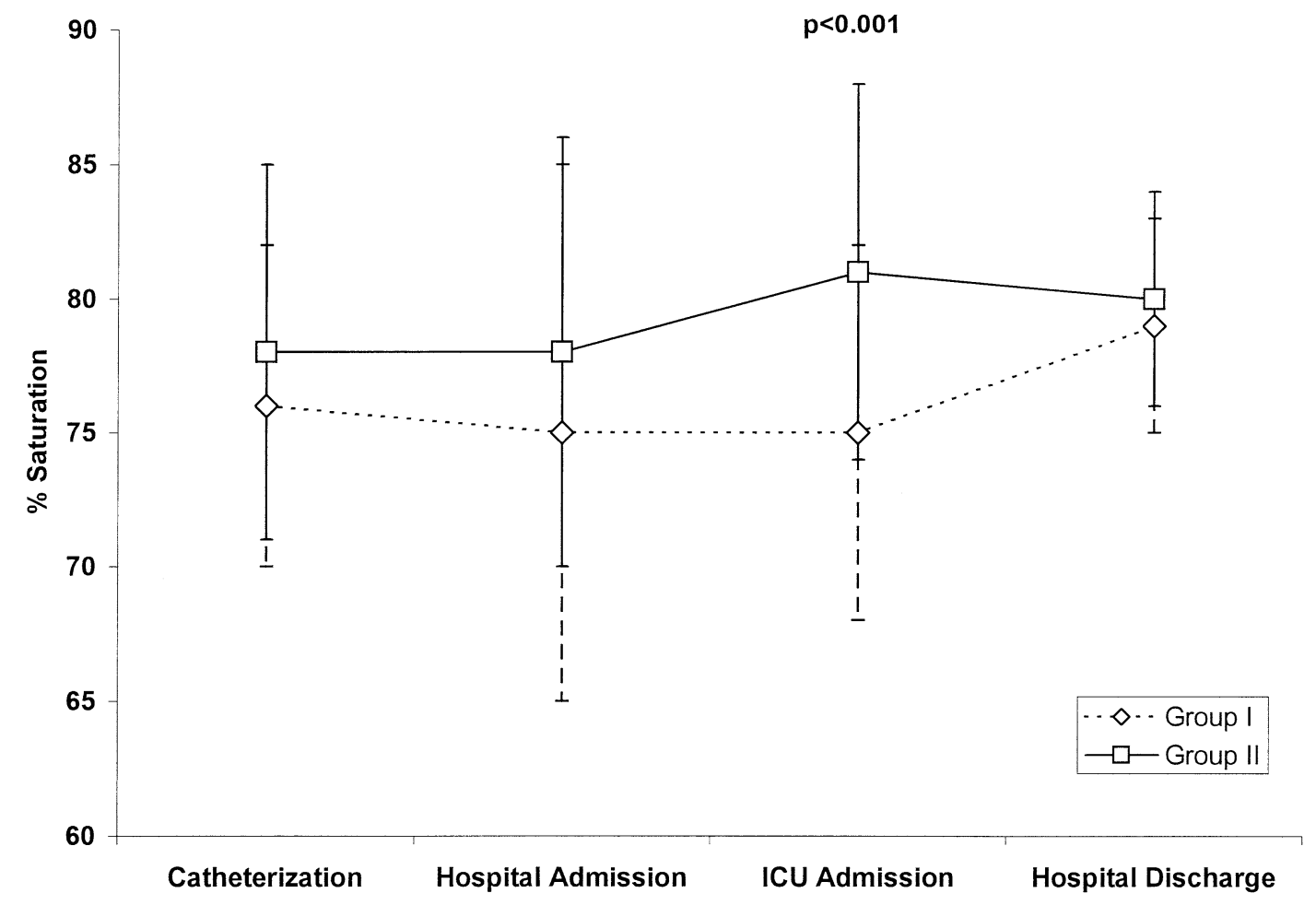

Figure 1. Oxygen saturations at various time points are shown. The groups were statistically significantly different only at ICU admission.

TABLE 3. Details of hospitalization

\begin{tabular}{|c|c|c|c|c|c|}
\hline \multirow[b]{2}{*}{ Variable } & \multicolumn{2}{|c|}{ Group I (n = 33) } & \multicolumn{2}{|c|}{ Group II (n= 52) } & \multirow[b]{2}{*}{$P$ value } \\
\hline & Mean \pm SD & $\begin{array}{c}\text { Median } \\
\text { (25th, 75th } \\
\text { percentile) }\end{array}$ & Mean \pm SD & $\begin{array}{c}\text { Median } \\
\text { (25th, 75th } \\
\text { percentile) }\end{array}$ & \\
\hline Mechanical ventilation (h) & $62 \pm 86$ & $23(9.2,95)$ & $19 \pm 42$ & $7(0,19)$ & .001 \\
\hline ICU stay (h) & $130 \pm 111$ & $93(69,127)$ & $104 \pm 94$ & $70(47,117)$ & .049 \\
\hline Pleural drainage $(\mathrm{h})$ & $106 \pm 45$ & $91(71,134)$ & $104 \pm 93$ & $71(63,103)$ & .046 \\
\hline Hospitalization (d) & $12.5 \pm 11.5$ & $8(6,13)$ & $10.3 \pm 14.8$ & $6(5,9)$ & .012 \\
\hline
\end{tabular}

Groups were compared by Mann-Whitney test for nonnormally distributed data. ICU, Intensive care unit.

CPA in group I (overwhelming enterovirus infection), and in group II there were 2 late deaths ( 1 suddenly 4.5 months after surgery, without autopsy, and 1 of overwhelming cytomegalovirus infection 2.5 months after surgery).

The likelihood of successful immediate postoperative extubation in the operating room was $13 \%$ in the younger group and $31 \%$ in the older group $(P=.068)$. Initial ICU hemodynamic data were very similar: superior vena caval pressure was $14 \pm 5 \mathrm{~mm} \mathrm{Hg}$ in the younger patients and 15 $\pm 5 \mathrm{~mm} \mathrm{Hg}$ in the older group $(P=.777)$. Likewise, atrial pressures were essentially the same in the 2 groups $(6 \pm 4$ $\mathrm{mm} \mathrm{Hg}$ in group I vs $5 \pm 4$ in group II; $P=.11$ ). The data for duration of ventilation, length of ICU stay, length of hospitalization, and duration of pleural drainage are presented in Table 3. Because these times were very prolonged in a few patients in each group, median values for each parameter are also presented. Correlation analysis showed age to be significantly negatively related to the duration of mechanical ventilation $(R=-0.4 ; P<.001)$, the duration of ICU stay $(R=-0.3 ; P=.01)$, and the length of hospital stay $(R=-0.3 ; P=.01)$, but not to the duration of chest tube drainage $(R=-0.2 ; P=.06)$.

\section{Oxygenation}

The $\mathrm{SaO}_{2}$ values recorded on admission to the hospital were similar (group I, $75 \% \pm 10 \%$; group II, $78 \% \pm 8 \% ; P=$ 
.106). On arrival in the ICU after surgery, the younger group had significantly lower $\mathrm{SaO}_{2}$ (group I, 75\% $\pm 7 \%$; group II, $81 \% \pm 7 \% ; P<.001)$. However, by the time of hospital discharge, this difference had vanished (group I, 79\% \pm 4\%; group II, $80 \% \pm 4 \% ; P=.120$ ). These data are shown graphically, along with the data obtained at preoperative cardiac catheterization, in Figure 1.

\section{Discussion}

As the care of children with congenital heart disease has evolved, there has been a continuing trend toward earlier intervention, on the basis of the premise that the sooner abnormal physiology can be normalized, the better the ultimate outcome. The limitations of this eminently logical principle have been both anatomic (size mismatch between relatively large instruments, catheters, bypass circuits, and so on) and physiologic, relating to the unique milieu of the neonate (increased pulmonary vascular resistance, tissue fragility, susceptibility to capillary leak syndrome, and so on). Nonetheless, the techniques of open cardiac operation in neonates and small infants can now be said to be well established.

Another important concept is that if a staged approach is necessary, then preliminary staging efforts should be planned and performed so as to optimize ultimate outcome. This concept is quite applicable to the management of children with univentricular hearts managed on a Fontan pathway, in whom staging should be performed in a fashion that minimizes pulmonary vascular resistance and optimizes systolic and diastolic ventricular performance. In such a scheme, the second-stage operation also affords an opportunity to resolve any residual hemodynamic abnormalities before Fontan completion. If achieved, the twin goals of a low transpulmonary gradient and a compliant ventricle functioning at minimal preload should promote the best early and late Fontan outcome.

When applied to infants with univentricular hearts and aortic obstruction in whom a Norwood operation has been performed, the principles of earliest intervention and best Fontan candidacy would suggest the earliest possible performance of cavopulmonary connection. Tempering the enthusiasm for this approach, however, are reports in which very young infants undergoing CPA were prone to severe hypoxemia, pulmonary artery thrombosis, and prolonged pleural effusions, with consequently prolonged hospitalization. ${ }^{1,2,8-10}$ In a group of children with heterogeneous diagnoses undergoing bidirectional cavopulmonary shunts, multiple regression analysis identified younger age as a predictor of lower postoperative $\mathrm{SaO}_{2} \cdot{ }^{13} \mathrm{In}$ a large group of patients undergoing second-stage operation, younger age was associated with a higher incidence of an adverse composite outcome (death and unsuitability for Fontan operation), although no specific breakpoint age could be identi- fied. ${ }^{10}$ A 2003 report from the Congenital Heart Surgeons Society has identified younger age at the time of operation as a risk factor for mortality after stage II operation. ${ }^{14}$

The data from this study would support previous observations that younger patients are at greater risk for postoperative hypoxemia. ${ }^{1,2,8,9}$ However, the initial postoperative $\mathrm{SaO}_{2}$ difference between groups was fairly small (75\% vs $81 \%$ ) and probably of minimal clinical significance. It is worth mentioning, though, that the younger group included a few patients with very low initial $\mathrm{SaO}_{2}$ values (in the range of $65 \%$ to $70 \%$ ), which gradually normalized over a period of days. The reason for early hypoxemia in younger patients is not clear but probably does not represent a baseline difference because the preoperative saturations, both in the cardiac catheterization laboratory and on admission to the hospital, were not different. Preoperative hemodynamic parameters were also not different between groups, nor were the postoperative determinations of superior vena caval pressure or atrial pressure. Thus, the difference in initial postoperative oxygenation cannot be explained on the basis of a higher initial transpulmonary gradient in the younger group. The durations of bypass time were not different between groups either. It is likely that the initial relative hypoxemia in younger patients simply represents an exaggerated susceptibility to bypass-induced injury in younger lungs, causing an early relative alveolar hypoxia, which resolves as the lung injury resolves. In a series of very young patients undergoing primary bidirectional Glenn shunts, Reddy and associates ${ }^{2}$ concluded that initial severe hypoxemia was clearly related to cardiopulmonary bypass because it was not seen in their patients who had the operation without bypass. In the present study, an alternative explanation for the initial arterial oxygenation difference would be a difference in initial venous oxygen saturation, reflecting a lower cardiac output in the younger group. Unfortunately, we did not routinely measure venous oxygen saturation and cannot confirm or refute this potential explanation. By whatever mechanism caused, the phenomenon of early hypoxemia in the younger patients was transient, as demonstrated by the fact that the $\mathrm{SaO}_{2}$ values at the time of discharge were the same in both groups.

Perhaps also explained by relatively immature bypassinjured lungs was the difference in the requirement for mechanical ventilation. This was best seen in the duration of mechanical ventilation, which was much longer in the younger group (mean duration of ventilation, 62 vs 19 hours). Because there were several children in the younger group who required prolonged ventilation, the median lengths of ventilation may be more representative (group I, 23 hours; group II, 7 hours), but still clearly conveyed is the excess early ventilator dependency in the young group. More patients in the older group were extubated in the operating room as well (31\% vs 13\%), although this differ- 
ence did not achieve statistical significance. Not surprisingly, the need for prolonged ventilation in the younger patients was associated with longer ICU stays (median ICU stay was 93 hours in group I and 70 hours in group II). Similarly, the duration of hospitalization was longer in the younger patients (median duration of hospitalization was 8 days in group I vs 6 days in group II). Likewise, there was a prolongation of pleural drainage in the younger group (median duration of pleural drainage was 91 hours in group I vs 71 hours in group II). This last finding is slightly surprising on the basis of essentially identical postoperative hemodynamics in the 2 groups. The most reasonable explanation is that pleural tubes were not removed until oral feeding was commenced, which in turn was typically approximately 1 day later in the younger group because of the longer duration of mechanical ventilation.

Postoperative low cardiac output syndrome was virtually unknown in either group, and this was reflected in the absence of early mortality for the entire cohort. This likely is an indication of the inherent significant hemodynamic benefit of ventricular unloading produced by conversion to CPA, as well as the rare need for adjunctive intracardiac procedures necessitating cardioplegic arrest. Intermediate mortality was also remarkably low, with an actuarial survival to 1 year of $96 \%$ in each group. This represents 1 late death in the younger group and 2 deaths in the older group.

Several limitations of this study must be acknowledged. Perhaps most importantly, the study was not performed in a prospective, randomized fashion. Furthermore, some patients underwent purely elective operation (typically the older patients), whereas others were operated on more urgently, such as those believed to have impending shunt thrombosis as detected by our home monitoring protocol ${ }^{7}$ (more likely in the younger group). This difference would be expected to bias in favor of worse outcome in the younger patients, but this was not seen. An additional limitation of the study is the use of end points that may be as reflective of physician behavior as patient physiology (duration of ventilation, ICU stay, hospital stay, and chest tube drainage). That such end points are "softer" than the more objective mortality and oxygenation data is undeniable, but such end points are clinically informative. Furthermore, the validity of these end points is enhanced by the retrospective nature of the study: physician behavior could not have been influenced in either group by a study that had not yet been initiated.

From these data, we conclude that performance of second-stage palliation in children who have undergone an initial Norwood operation is as safe at less than 4 months of age as it is at more than 4 months of age, albeit with more resource utilization in the younger group. The major cost of early CPA seems to be a transient relatively minor hypoxemia and an associated requirement for mechanical venti- lation, which in turn leads to more time in the ICU and a longer hospital stay. In contrast, the benefits of earlier operation, which are predominantly to be expected in relation to the Fontan completion, remain hypothetical. Continued close follow-up of this cohort will be necessary to determine whether the suggested benefits of early secondstage operation are in fact manifested as better early and long-term outcomes after the Fontan operation. Finally, it is worth noting that the absence of mortality or permanent morbidity in the younger patients in this study implies that the question of how young is too young remains unanswered. In fact, if the major determinant of timing of CPA is the normalization of pulmonary vascular resistance, which in children with normal hearts is nearly at its nadir by 2 weeks, ${ }^{15-19}$ it is intriguing to consider the possibility of a rapid 2-stage approach with an initial Norwood operation followed weeks later by conversion to a CPA.

\section{References}

1. Chang AC, Hanley FL, Wernovsky G, Rosenfeld HM, Wessel DL, Jonas RA, et al. Early bidirectional cavopulmonary shunt in young infants. Postoperative course and early results. Circulation. 1993;88(5 Pt 2):II149-58.

2. Reddy VM, Liddicoat JR, Hanley FL. Primary bidirectional superior cavopulmonary shunt in infants between 1 and 4 months of age. Ann Thorac Surg. 1995;59:1120-5; discussion 1125-6.

3. Jacobs ML, Rychik J, Rome JJ, Apostolopoulou S, Pizarro C, Murphy JD, et al. Early reduction of the volume work of the single ventricle: the hemi-Fontan operation. Ann Thorac Surg. 1996;62:456-61; discussion 461-2.

4. Fogel MA, Rychik J, Vetter J, Donofrio MT, Jacobs M. Effect of volume unloading surgery on coronary flow dynamics in patients with aortic atresia. J Thorac Cardiovasc Surg. 1997;113:718-26; discussion 726-7.

5. Azakie T, Merklinger SL, McCrindle BW, Van Arsdell GS, Lee KJ, Benson LN, et al. Evolving strategies and improving outcomes of the modified Norwood procedure: a 10-year single-institution experience. Ann Thorac Surg. 2001;72:1349-53.

6. Mahle WT, Spray TL, Gaynor JW, Clark BJ III. Unexpected death after reconstructive surgery for hypoplastic left heart syndrome. Ann Thorac Surg. 2001;71:61-5.

7. Ghanayem NS, Hoffman GM, Mussatto KA, Cava JR, Frommelt PC, Rudd NA, et al. Home surveillance program prevents interstage mortality after the Norwood procedure. J Thorac Cardiovasc Surg. 2003; 126:1367-77.

8. Bradley SM, Mosca RS, Hennein HA, Crowley DC, Kulik TJ, Bove EL. Bidirectional superior cavopulmonary connection in young infants. Circulation. 1996;94(9 suppl):II5-11.

9. Slavik Z, Lamb RK, Webber SA, Devlin AM, Keeton BR, Monro JL, et al. Bidirectional superior cavopulmonary anastomosis: how young is too young? Heart. 1996;75:78-82.

10. Douglas WI, Goldberg CS, Mosca RS, Law IH, Bove EL. HemiFontan procedure for hypoplastic left heart syndrome: outcome and suitability for Fontan. Ann Thorac Surg. 1999;68:1361-8.

11. Tweddell JS, Berger S, Frommelt PC, Pelech AN, Lewis DA, Fedderly RT, et al. Aprotinin improves outcome of single-ventricle palliation. Ann Thorac Surg. 1996;62:1329-35.

12. Jaquiss RD, Ghanayem NS, Zacharisen MC, Mussatto KA, Tweddell JS, Litwin SB. Safety of aprotinin use and re-use in pediatric cardiothoracic surgery. Circulation. 2002;106(12 suppl 1):I90-4.

13. Aeba R, Katogi T, Kashima I, Omoto T, Kawada S, Omae K. Factors influencing arterial oxygenation early after bidirectional cavopulmonary shunt without additional sources of pulmonary blood flow. J Thorac Cardiovasc Surg. 2000;120:589-95. 
14. Ashburn DA, McCrindle BW, Tchervenkov CI, Jacobs ML, Lofland GK, Bove EL, et al. Outcomes after the Norwood operation in neonates with critical aortic stenosis or aortic valve atresia. J Thorac Cardiovasc Surg. 2003;125:1070-82.

15. Rowe RD, James LS. The normal pulmonary arterial pressure during the first year of life. J Pediatr. 1957;51:1-4.

16. Akiba T, Akiba K. Continuous-wave Doppler echocardiographic evaluation of the changes in pulmonary arterial pressure during the first seven days of life. Am J Cardiol. 2002;89:479-81.

17. Haworth SG, Hislop AA. Adaptation of the pulmonary circulation to extra-uterine life in the pig and its relevance to the human infant. Cardiovasc Res. 1981;15:108-19.

18. Adams FH, Lind J. Physiologic studies on the cardiovascular status of normal newborn infants (with special reference to the ductus arteriosus). Pediatrics. 1957;19:431-7.

19. Rudolph AM. The changes in the circulation after birth. Their importance in congenital heart disease. Circulation. 1970;41:343-59.

\section{Discussion}

Dr David Campbell (Denver, Colo). Dr Jaquiss, I want to congratulate you on an excellent presentation here this morning and also commend you and your colleagues for the fine work that you have done. It is well known the kind of results that you have had at the Children's Hospital of Wisconsin Milwaukee over the last few years with hypoplastic left heart syndrome. I'll make comments that involve information from the manuscript as well as from your excellent presentation this morning.

This is a retrospective study that compares the outcomes of the authors' most recent 85 consecutive post-stage I Norwood procedure infants when divided into 2 separate groups, group I having undergone early conversion to cavopulmonary anastomosis or cavopulmonary shunt at less than 4 months of age (33 patients) and group II having undergone conversion at greater than 4 months of age ( 52 patients). The stated recent bias of the institution, I believe, is to perform the conversion to cavopulmonary anastomosis at an earlier and perhaps earlier age. This brings me to my first question. It is not entirely clear to me why the group I children came to early conversion. Was it an individual attending physician decision, urgent rather than elective conversion because of impending complications that you mentioned, such as shunt thrombosis, or a change in institutional bias toward earlier elective conversion during the later part of the study? Could you clarify this if possible?

Dr Jaquiss. There was a tendency for more children in the younger group to have impending shunt thrombosis, but it is a general bias that we should go earlier. There was no standardized approach.

Dr Campbell. Well, the reason that I asked this question, and it may seem intuitively obvious at first, is that looking at the data from your manuscript, 33\% of group I patients required concomitant aortic arch or pulmonary artery repairs, but only $15 \%$ of group II patients required these repairs. The group I patients are the more recently operated-on patients, I suppose, and they were certainly not all emergencies, yet they have a much higher incidence of associated complications. Could you comment on this?

Dr Jaquiss. The group I patients, those undergoing arch revision, include a small number of patients who had aortic arch reconstruction by using the Cryolife Synergraft pulmonary artery patch, which we had unfortunately very bad results with in terms of shrinkage and arch narrowing. There were very few patients, in fact, I don't think any, in the older group who got that, and that, I think, accounts for the difference in concomitant arch reconstruction. Other procedures were essentially the same between groups.

Dr Campbell. The results in both groups are impressive, with no hospital mortality in either group, and early actuarial survival was $96 \%$ in both groups to 1 year of age, though a small price was paid, as you pointed out. Early postoperative oxygen saturations were lower, although they did at the time of discharge become similar. Mechanical ventilation, ICU length of stay, pleural drainage, and hospitalization were longer in the group I children. My second question is this: during the period of the study, what was your actual interstage mortality between stage I and stage II? I know you have commented on this in other articles, but I know you also have presented work suggesting that the interstage mortality can be decreased substantially by home monitoring. Could you comment on this?

Dr Jaquiss. During the period described by the study, we had 4 interstage deaths. In the last 2 years, we have had 1 death. I can't remember the denominator for the entire Norwood population, but I guess it would be 4 plus the 85 .

Dr Campbell. So you have shown, I believe, that conversion to cavopulmonary anastomosis at 4 months or less of age at your institution is safe. The question I have is, is it necessary? To put it differently, is it unsafe to wait? There are several reports, the most recent by Ashburn, which I am sure you are aware of since you did comment on this in your paper from the Congenital Heart Surgeons Society that was presented last year at the American Thoracic Society but came out in print just 1 month ago in May 2003, which did suggest that younger age is a significant risk factor for death after conversion of stage I Norwood children to the cavopulmonary shunt.

Finally, do you have any data to suggest that the older group, ie, those infants who had cavopulmonary conversion after 4 months of age, are experiencing a worse outcome after completion of the Fontan, since this would be the group of patients who have had longer periods of volume overload and a greater risk of higher pulmonary artery resistances?

Dr Jaquiss. I don't have any data at all to support the theory that I advance that it is better to have surgery done earlier on the basis of older patients having worse post-Fontan outcomes, and like a lot of things in congenital heart surgery, unfortunately those kinds of consequences will be seen only years or, more likely, decades later. I think the physiologic rationale for conversion is inarguable, and it all revolves around the question of whether there is a mortality or morbidity risk that is significant enough to prevent you from going earlier. The paper from the Congenital Heart Surgeons Society is an excellent one and, like all of their papers, is well researched with incredibly sound statistics, but it is a multi-institutional study looking at the absolute worst subpopulation of hypoplastic syndrome, those with aortic atresia, although we had a significant percentage of those kids, and I'm not sure that I would agree that their conclusions are generalizable into contemporary 2003 practice.

Dr Campbell. Yes, but I think that may be an important concept, at least as far as I'm concerned, because there certainly are institutions such as yours that have excellent results with this lesion. There are others that might have been in that study, in the multi-institutional study, that do not have as good results, so it is not necessarily obvious that you must carry out the same kind of 
procedure at those institutions with maybe worse results. So when you suggest that things are safe, that's why I say it is safe at your institution, but maybe not necessarily at others. Now having said all this, my bias is toward early conversion to the cavopulmonary shunt, and as more institutions move toward earlier and earlier conversion, the question of how young is too young, I am certain, will be answered.

Dr Winfield Wells (Los Angeles, Calif). Just 1 short question. I am wondering if any of the patients received nitric oxide after their bidirectional Glenn.

Dr Jaquiss. I don't have that in the manuscript. I don't have the data, but I can recall anecdotally 1 . The child who had the pul- monary artery thrombosis who was a very young patient was incredibly hypoxemic 2 days postoperatively, and among the many things that were done as that child was taken down for angiography was the addition of nitric oxide, which had absolutely no benefit.

Dr Wells. Okay, but no other patients.

Dr Jaquiss. Not that I can recall.

Dr Wells. And just finally, summarizing a little bit of what has been said, would you now be willing to restate some of the final conclusions, that is to say, that you have proven that this is safe in your institution but you have no evidence that it is beneficial.

Dr Jaquiss. Yes, I think that's fair.

Now you can get The Journal of Thoracic and Cardiovascular Surgery online. The Journal online brings you faster delivery time, easy searching of current and back issues, links to PubMed, AATS, WTSA, and other important sites, and more. Visit the Journal online today.

\section{Receive tables of contents by e-mail}

To receive the tables of contents by e-mail, sign up through our Web site at http://www.mosby.com/jtcvs

Choose E-mail Notification

Simply type your e-mail address in the box and click the Subscribe button. Alternatively, you may send an e-mail message to majordomo@mosby.com. Leave the subject line blank and type the following as the body of your message: subscribe jtcvs_toc

You will receive an e-mail to confirm that you have been added to the mailing list.

Note that TOC e-mails will be sent out when a new issue is posted to the Web site. 